\title{
Intimate Partner Violence \\ Victimization and \\ Mental Health Among \\ Men Who Have Sex \\ With Men Living With \\ HIV in Guatemala
}

Journal of Interpersonal Violence 2022, Vol. 37(3-4) NPI637-NPI657

(C) The Author(s) 2020

(c) (i) (3)

Article reuse guidelines: sagepub.com/journals-permissions DOI: I0.I I77/0886260520928960 journals.sagepub.com/home/jiv

@SAGE

\author{
Dirk A. Davis, MPH' (D, \\ Amelia Rock, MS', \\ Renato Santa Luce, MD, MPH², \\ Luz McNaughton-Reyes, PhD' \\ and Clare Barrington, PhD'
}

\begin{abstract}
Gay, bisexual, and other men who have sex with men (MSM) are disproportionately affected by poor mental health compared to their heterosexual counterparts. One factor that may increase mental health problems among MSM is intimate partner violence (IPV) victimization. The objectives of this study are to (a) describe the prevalence of different forms of IPV victimization experienced by MSM living with HIV in Guatemala City and (b) examine the relationship between IPV victimization and mental health.
\end{abstract}

\footnotetext{
'The University of North Carolina at Chapel Hill, USA

${ }^{2}$ Universidad del Valle de Guatemala, Guatemala City, Guatemala
}

\section{Corresponding Author:}

Dirk A. Davis, Department of Health Behavior, Gillings School of Global Public Health, The University of North Carolina at Chapel Hill, I35 Dauer Drive 302 Rosenau Hall, CB \#7440 Chapel Hill, NC 27599-7440, USA.

Email: dirkd@live.unc.edu 
We analyzed cross-sectional survey data from a cohort of MSM living with HIV in Guatemala City $(n=374)$ to describe the burden of IPV, including physical, sexual, and emotional IPV. We then examined relationships between lifetime IPV and each form of recent IPV (past 12 months) with self-reported anxiety and depression using multivariable logistic regression. Over a quarter $(27.3 \%)$ of the participants screened positive for anxiety and nearly one fifth (17.9\%) screened positive for depression. Over a quarter of the participants $(28.6 \%)$ reported ever having experienced any IPV victimization and $8.8 \%$ reported having experienced any form of recent IPV. In multivariable analyses, participants who experienced any form of lifetime IPV had roughly twice the odds of experiencing anxiety (OR: I.86; 95\% $\mathrm{Cl}=[\mathrm{I} .03,3.38])$ and depression (OR: $2.02 ; 95 \% \mathrm{Cl}=[\mathrm{I} .02,3.99]) \mathrm{com}-$ pared to those who had not. Participants who experienced recent emotional IPV had over seven times the odds of experiencing anxiety (OR: 7.23; $95 \% \mathrm{Cl}=[\mathrm{I} .46,38.85])$ compared to those who had not. MSM living with $\mathrm{HIV}$ in Guatemala experience a high burden of anxiety, depression, and IPV victimization. Those participants who had experienced lifetime IPV and recent emotional IPV were significantly more likely to screen for anxiety and depression. To improve their mental health, HIV clinics and other health services should provide support for MSM who have experienced IPV victimization.

\section{Keywords}

intimate partner violence, mental health, men who have sex with men, HIV, and Guatemala

\section{Background}

Gay, bisexual, and other men who have sex with men (MSM) are disproportionately affected by poor mental health outcomes, including depression and anxiety, compared to their heterosexual counterparts (Batchelder et al., 2017; Cochran \& Mays, 2009; King et al., 2008; O'Cleirigh et al., 2015). Specifically for MSM living with HIV, both depression and anxiety are associated with missing HIV care appointments and poor treatment adherence (Batchelder et al., 2017; Brandt et al., 2016; Campos et al., 2010; Friedman et al., 2015; O'Cleirigh et al., 2013). One factor that may increase the risk for mental health problems among MSM living with HIV is intimate partner violence (IPV) victimization. IPV includes physical abuse (e.g., slapping, hitting, kicking, and 
beating), sexual abuse (e.g., forced sexual intercourse and sexual coercion), and emotional abuse (e.g., insults, belittling, humiliation, intimidation, and threats of harm) by an intimate partner, such as a boyfriend or husband (World Health Organization, 2002).

MSM have historically been excluded from public health discourse and research on IPV victimization, which has been guided by a heteronormative lens that frames IPV as occurring between male perpetrators and female victims (Cannon \& Buttell, 2015; Letellier, 1994). As Cannon and Buttell (2015) argue, this framing of IPV as a manifestation of patriarchal norms related to male dominance over women prevents men in same-sex relationships from being recognized as victims, and has contributed to the minimization of violence between male partners as simply fighting or "typical" male behavior. Researchers have highlighted the need to recognize IPV as a function of complex interactions between culture, social structures, social status, and interpersonal dynamics among men (Baker et al., 2013; Cannon \& Buttell, 2015).

This new framing of IPV is necessary as evidence suggests that MSM are at a high risk for IPV victimization (Greenwood et al., 2002; Pantalone et al., 2014). A recent meta-analysis of 19 studies primarily from the United States (US) reported a pooled prevalence of $32.0 \%$ $(95 \% \mathrm{CI}=[19.32,44.58])$ of any form of IPV victimization in the previous 5 years for MSM (Buller et al., 2014). A separate systematic review of 28 studies from the United States also found a high prevalence of IPV victimization among MSM, ranging from $32.4 \%$ to $78.0 \%$, including physical violence $(11.8 \%-45.1 \%)$, sexual violence $(5.0 \%-$ $33.3 \%$ ), and psychological violence $(33.0 \%-73.2 \%$ ) (Finneran \& Stephenson, 2013). MSM living with HIV are even more likely than MSM not living with HIV to report various forms of violence (Greenwood et al., 2002; Pantalone et al., 2014; Pantalone et al., 2012). For example, in one large study in urban centers in the United States, MSM living with HIV had higher odds of reporting physical IPV over the past five years (OR 1.5; 95\% CI $=[1.1,2.1]$ ) compared to MSM not living with HIV (Greenwood et al., 2002).

IPV among MSM has been associated with negative mental health outcomes (Buller et al., 2014; Houston \& McKirnan, 2007; Stall et al., 2003). A meta-analysis from the United States that measured associations between IPV and mental health among MSM found that men exposed to any kind of IPV had increased odds of self-reported depressive symptoms (pooled OR 1.52, 95\% CI $=[1.24,1.86], I^{2}=9.9 \%, 95 \%$ $\mathrm{CI}_{I}^{2}=0 \%-91 \%$ ) (Buller et al., 2014). Only one study has examined the relationship between IPV and mental health among MSM living with 
HIV. Among MSM living with HIV in Seattle, $(n=168)$, Pantalone et al. (2012) found that compared to men not reporting physical IPV, those who reported past year physical IPV had higher average scores on measures of anxiety ( 2.4 vs. $1.8 ; t=-4.1, p<.001)$, depressive symptoms ( 26.2 vs. $18.4 ; t=-3.2, p<.01$ ), and suicidal ideation (1.0 vs. 0.6 ; $t=-2.5, p=.01)$. Men who reported past year physical IPV also reported lower health-related quality of life (HRQOL) (3.0 vs. 3.2; $t=2.0, p=.05$ ) than men not reporting past year physical IPV (Pantalone et al., 2012).

Understanding the associations between IPV victimization and mental health outcomes among MSM living with HIV is critical for improving health outcomes among this population. The objectives of this study are the following: (a) to describe the prevalence of different forms of IPV victimization - physical, sexual, and emotional - experienced by MSM living with HIV in Guatemala City and (b) to examine the relationship between IPV victimization and mental health in this population.

\section{Methods}

\section{Study Setting}

We used baseline data from an implementation science project to decentralize HIV care among MSM $(n=374)$ in Guatemala City, the capital of Guatemala (Barrington et al., 2020). MSM in Guatemala are disproportionally affected by HIV with a prevalence of $10.5 \%$ compared to $0.8 \%$ among adults in the general population (Guardado Escobar et al., 2017). The rates of violence in the general population and IPV in heterosexual couples in Guatemala are among the highest in the world (United Nations Human Rights Council, 2018). One study from Guatemala reported a high prevalence of violence experienced by MSM (psychological: $29.8 \%$, verbal: $38.2 \%$, physical: $20.2 \%$, and sexual: $6.4 \%$ ); however, the researchers did not ask about the nature of the relationship between victims and perpetrators and so it is not possible to determine whether this violence constitutes IPV (Wheeler et al., 2014).

The study was reviewed and approved by the Ethics Committee for the Protection of Human Subjects of the Guatemalan Ministry of Health and the Universidad del Valle de Guatemala, the Institutional Review Board of the University of North Carolina at Chapel Hill, and by the CDC Center for Global Health (CGH) Office of the Associate Director for Science/Laboratory Science (ADS/ADLS). 


\section{Recruitment}

Between January and June 2017, we purposively recruited 374 MSM living with HIV who met the eligibility criteria of being at least 18 years old, male, self-reported ever having sex with men, spoke and understood Spanish, and received HIV care and treatment at the Hospital Roosevelt Infectious Disease Clinic in Guatemala City. Partners at Hospital Roosevelt generated a list of 445 eligible patients. As the individuals from the list arrived for their regular clinic appointments over the recruitment period, the study staff described the study to them and invited them to participate, eventually enrolling 374 participants (84\% acceptance). All participants provided the informed consent.

\section{Procedures}

Baseline data were obtained from socio-behavioral surveys administered by trained interviewers between January and June 2017. All surveys were conducted in Spanish in private locations at the study sites using tablets. Survey items were developed based on published measures in the global HIV literature, our team's previous work in Guatemala, and input from key stakeholders. Surveys were piloted for comprehension and acceptability.

\section{Measures}

\section{Dependent variables}

Anxiety. We screened for anxiety using the 2-item Generalized Anxiety Disorder assessment (GAD-2). Participants were asked how often they had been bothered by (a) feeling nervous, anxious, or on edge and (b) feeling worried and incapable of controlling their worry, over the past 2 weeks (Plummer et al., 2016). Response categories for each item were as follows: $0=$ not at all, $1=$ several days, $2=$ most days, and $3=$ nearly every day. The scores on the two items were summed (range 0-6), with a score of 3 considered the optimal cut-point for screening purposes. We created a new dichotomous anxiety variable based on the summed score where participants with a score of 3 or more were considered screening positive for anxiety. The item correlation was $.66(p<.001)$ for the two anxiety items in our sample.

Depression. We used the 2-item Patient Health Questionnaire (PHQ2) to assess depressive symptoms (Kroenke et al., 2003). Participants were asked how often they had been bothered by (a) having little 
interest or pleasure in doing things and (b) feeling down, depressed, or hopeless, over the last 2 weeks. The participants again responded with a frequency across 4 categories $(0=$ not at all, $1=$ several days, $2=$ most days, and $3=$ nearly every day). The PHQ-2 score ranges from 0 to 6 , with a score of 3 considered the optimal cut-point for screening purposes (Kroenke et al., 2003). We coded a new dichotomous depression variable to 1 , representing screening positive for depression, for participants with a score of 3 or more. The item correlation was .48 $(p<.001)$ for the two depression items in our sample.

\section{Independent variables}

Intimate partner violence victimization. We assessed lifetime and recent (past 12 months) IPV by asking the participants to respond "yes" or "no" to two questions: (a) "have you ever been mistreated by any of your sexual partners?" and (b) "in the last 12 months, have you been mistreated by any of your sexual partners?" If they responded "yes" to the second question, they were then asked "what kind of mistreatment have you experienced from a sexual partner in the last 12 months?." Participants were considered victims of physical IPV if they had a sexual partner hit, push, kick, pull hair, throw objects, strangle or burn them; of sexual IPV if they experienced any type of sexual activity with another person without giving consent; and of emotional IPV if a partner threatened, insulted, humiliated, screamed at, or controlled them. These definitions were drawn from the WHO's guidelines on IPV (World Health Organization, 2002).

\section{Covariates}

Demographics. Participants reported their age, sexual orientation (SO), highest level of education, employment status, civil status, current relationship status, ethnicity, and time since HIV diagnosis.

Alcohol Use Disorder (AUD). In studies with MSM, substance use (alcohol and drugs) has been found to be associated with both IPV victimization and mental health outcomes (Buller et al., 2014; Dyer et al., 2012; Houston \& McKirnan, 2007; Pantalone et al., 2012; Stall et al., 2003). We assessed alcohol use with the 11-item DSM-5 Alcohol Use Disorder (AUD) assessment. Participants were asked to respond "yes" or "no" to questions about alcohol use over the past 12 months. Scores from the 11 items were summed (range 0-11) and participants who responded "yes" to two or more of the criteria were considered to have AUD. In addition, we created new variables for mild AUD for participants who met between two and three criteria; moderate AUD for participants 
who met between four and five criteria; and severe AUD for participants who met six criteria or more (for descriptive analysis). For the current study, the DSM-5 AUD scale demonstrated a Cronbach's alpha of 0.92 .

Drug use. We assessed drug use by asking the participants to respond "yes" or "no" to "in the past 6 months, have you used illegal drugs? Illegal drugs are those prohibited by law." If a participant responded "yes," we coded a dichotomous drug use variable to 1.

Nondisclosure of SO. Based on the Minority Stress Theory (MST), nondisclosure of SO may affect the mental health of sexual minorities (Meyer, 1995, 2007). We assessed if a participant was considered "out" about their SO by asking "who have you told that you have sex with men (or are gay, homosexual, bisexual, etc.)?" Response options were $1=$ no one, $2=$ father, mother or both, $3=$ siblings, $4=$ classmates, $5=$ colleagues, $6=$ friends, $7=$ sexual partner, $8=$ children, $9=$ neighbors, and $10=$ everyone. If the participants responded that they were not out to anyone or only to sexual partners, we considered them not out and created a dichotomous nondisclosure of the $\mathrm{SO}$ variable.

School SO bullying. Extensive research demonstrates a positive correlation between school SO bullying based on perceived SO among sexual minority youth and subsequent mental health outcomes (McKay et al., 2017; McNamee et al., 2008; Russell et al., 2011). To assess if the participants had experienced school bullying based on perceived SO, we asked "when you were a child or adolescent, how often did you experience abuse or mistreatment in school because someone thought you were gay?" Response options were $1=$ never, $2=$ rarely, $3=$ occasionally, and $4=$ frequently. We dichotomized this variable and coded it as 1 for anyone who reported experiencing school SO bullying (responding rarely, occasionally, or frequently).

MSM stigma. To assess stigma based on SO, we asked the participants to respond "yes" or "no" to the question "in the past 12 months, have you experienced any type of mistreatment for being a man who has sex with men (gay, homosexual, bisexual, etc.)?." We coded "yes" responses to 1.

\section{Data Analysis}

Demographic characteristics of the study participants and covariates are presented in Table 1. To evaluate our first aim, we estimated the 
Table I. . Sociodemographic Characteristics of MSM Living With HIV in Guatemala $(n=374)$.

\begin{tabular}{|c|c|c|}
\hline Characteristics & $N$ & $\%$ \\
\hline \multicolumn{3}{|l|}{ Age } \\
\hline & 32.6 (mean) & 18-63 (range) \\
\hline \multicolumn{3}{|l|}{ Sexual orientation } \\
\hline Heterosexual & 8 & 2.1 \\
\hline Bisexual & 88 & 23.5 \\
\hline Homosexual/gay & 278 & 74.3 \\
\hline \multicolumn{3}{|l|}{ Disclosed sexual orientation } \\
\hline Yes & 351 & 93.8 \\
\hline No & 23 & 6.2 \\
\hline \multicolumn{3}{|l|}{ Education } \\
\hline No schooling & 4 & I.I \\
\hline Some/completed primary & 31 & 8.3 \\
\hline Some/completed secondary & 166 & 44.4 \\
\hline Some/completed college & 173 & 46.3 \\
\hline \multicolumn{3}{|l|}{ Currently employed } \\
\hline Yes & 290 & 77.5 \\
\hline No & 84 & 22.5 \\
\hline \multicolumn{3}{|l|}{ Ethnicity } \\
\hline Ladino (nonindigenous) & 330 & 89.4 \\
\hline Maya/Xinca (indigenous) & 33 & 8.9 \\
\hline Garífuna/Others & 6 & 1.6 \\
\hline \multicolumn{3}{|l|}{ Ever had a stable partner? } \\
\hline Yes & 272 & 72.7 \\
\hline No & 102 & 27.3 \\
\hline \multicolumn{3}{|l|}{ Drug use } \\
\hline Yes & 35 & 9.4 \\
\hline No & 339 & 90.6 \\
\hline \multicolumn{3}{|l|}{ Alcohol Use Disorder } \\
\hline Mild & 44 & 11.8 \\
\hline Moderate & 19 & 5.1 \\
\hline Severe & 39 & 10.4 \\
\hline None & 272 & 72.7 \\
\hline \multicolumn{3}{|l|}{ MSM stigma } \\
\hline Yes & 76 & 20.3 \\
\hline No & 298 & 79.7 \\
\hline \multicolumn{3}{|c|}{ School sexual orientation bullying } \\
\hline Yes & 198 & 52.9 \\
\hline No & 176 & 47.1 \\
\hline \multicolumn{3}{|l|}{ Years since HIV diagnosis } \\
\hline & 4 (mean) & 0-29 (range) \\
\hline
\end{tabular}

Note. $M S M=$ men who have sex with men; HIV = human immunodeficiency virus. 
prevalence of any form of lifetime IPV, any form of recent IPV (over the past 12 months), and the three different forms of recent IPV (physical, sexual, and emotional). In addition, we estimated the prevalence of experiencing multiple forms of recent IPV (physical and sexual, physical and emotional, sexual and emotional, and all three forms). Using logistic regression, we examined bivariate associations between each of the IPV variables, potential covariates, and anxiety and depression. We considered inclusion of covariates given evidence in the literature and/or theoretical plausibility of their associations with mental health outcomes (Kubicek, 2018; Meyer, 2007). For example, among MSM, substance use (alcohol and drugs) is associated with both IPV victimization and mental health outcomes and were therefore included as covariates. We then used multivariable logistic regression to assess the unique effects of each form of IPV on anxiety and depression (separate models) controlling for covariates. For each outcome (anxiety and depression) we ran two models: the first examined the measures of lifetime IPV (any IPV experienced over the life course) and the second examined IPV over the past 12 months (recent IPV). Due to the low prevalence of recent physical and sexual IPV, we combined these and created one variable of recent physical or sexual IPV for this model. We first ran the recent IPV models with just recent physical or sexual IPV and recent emotional IPV to determine if significant associations with depression and anxiety existed before adding in covariates. In all models, we controlled for age, ethnicity, alcohol use disorder, drug use, nondisclosed SO, school SO bullying, and MSM stigma. We also controlled for depression in the anxiety models and for anxiety in the depression models. Analyses were conducted using SAS version 9.4.

\section{Results}

\section{Sample Characteristics}

As reported in Table 1, the mean age was 32.6 years (range: 18-63). The majority of the participants self-identified as homosexual or gay $(74.3 \%)$ and Ladino (nonindigenous) $(89.4 \%)$. Nearly half $(46.3 \%)$ had at least some college education and the majority $(77.5 \%)$ were employed at the time of survey. Nearly three quarters of the participants reported ever having a stable partner $(72.7 \%)$. The mean time since HIV diagnosis was 4.3 years (range: $0-29)$. Over a quarter $(27.3 \%)$ of the participants screened positive for AUD, $11.8 \%$ with mild AUD, $5.1 \%$ with moderate AUD, and $10.4 \%$ with severe AUD. Nearly one 
tenth $(9.4 \%)$ reported using illegal drugs over the past 6 months. In addition, over half $(52.9 \%)$ reported experiencing school bullying based on SO and a fifth $(20.3 \%)$ reported experiencing stigma based on their SO over the past 12 months.

\section{Prevalence of IPV Victimization, Anxiety, and Depression}

As seen in Table 2, more than a quarter $(n=102,27.3 \%)$ of the participants screened positive for anxiety and nearly one fifth $(n=67,17.9 \%)$ screened positive for depression. Over a quarter of the participants $(n=107,28.6 \%)$ reported ever having experienced any IPV and $8.8 \%$ $(n=33)$ reported having experienced any form of recent (past 12 months) IPV. The most common form of recent IPV was emotional $(n=29,7.8 \%)$, followed by physical $(n=22,5.9 \%)$ and sexual $(n=7$, $1.9 \%)$. Among those that experienced recent IPV victimization $(n=33)$, $63.6 \%(n=21)$ reported experiencing two or more forms, the most common combination being physical and emotional $(n=19,57.6 \%)$ while $12.1 \%(n=4)$ reported experiencing all three forms of recent IPV.

Table 2. Prevalence of Anxiety, Depression, and IPV Victimization Among MSM Living With HIV in Guatemala $(n=374)$.

\begin{tabular}{lcc}
\hline Mental Health and IPV & $n$ & $\%$ \\
\hline Mental health & 102 & \\
$\quad$ Screened positive for anxiety & 67 & 27.3 \\
$\quad$ Screened positive for depression & 107 & 17.9 \\
Any lifetime IPV & 267 & 28.6 \\
$\quad$ Yes & & 71.4 \\
No & 33 & 8.8 \\
Any recent IPV (past I2 months) & 34 I & 91.2 \\
$\quad$ Yes & & \\
No & 29 & 7.8 \\
Single forms of recent IPV (past I2 months) & 22 & 5.9 \\
$\quad$ Emotional & 7 & 1.9 \\
Physical & & \\
Sexual & 19 & 57.6 \\
Multiple forms of recent IPV (past I2 months) & 6 & 18.2 \\
$\quad$ Physical and emotional & 4 & 12.1 \\
$\quad$ Physical and sexual & 4 & 12.1 \\
$\quad$ Sexual and emotional & & \\
Physical, emotional, and sexual &
\end{tabular}

Note. IPV = intimate partner violence. 


\section{Bivariate Associations}

Bivariate associations between IPV victimization variables and anxiety and depression are presented in Table 3. Associations with $p$-values equal to or less than .05 were considered statistically significant. Any form of lifetime IPV, recent physical or sexual IPV, recent emotional IPV, and experiencing multiple forms of recent IPV were all significantly associated with both anxiety and depression. Age, ethnicity and AUD were significantly associated with anxiety; age and AUD were also significantly associated with depression; and anxiety and depression were significantly associated with one another.

\section{Multivariate Analyses}

In multivariate analyses, MSM living with HIV who experienced any form of lifetime IPV had significantly higher odds of experiencing anxiety $(\mathrm{OR}: 1.86 ; 95 \% \mathrm{CI}=[1.03,3.38])$ and depression $(\mathrm{OR}: 2.02 ; 95 \%$ $\mathrm{CI}=[1.02,3.99])$ compared to those who had not, after adjusting for study covariates (Table 4). We found a significant association between recent emotional IPV and anxiety (OR: $7.23 ; 95 \% \mathrm{CI}=[1.46,38.85])$,

Table 3. Bivariate Associations Between IPV, Study Covariates and Mental Health Outcomes Among MSM Living With HIV in Guatemala $(n=374)$.

\begin{tabular}{|c|c|c|c|c|c|c|}
\hline \multirow[b]{2}{*}{ Variables } & \multicolumn{3}{|c|}{ Anxiety } & \multicolumn{3}{|c|}{ Depression } \\
\hline & OR & $95 \% \mathrm{Cl}$ & $p$ Value & OR & $95 \% \mathrm{Cl}$ & $p$ Value \\
\hline Any lifetime IPV & 2.10 & {$[1.29,3.40]$} & $<.01$ & 2.42 & {$[1.40,4.18]$} & $<.01$ \\
\hline $\begin{array}{l}\text { Recent physical or } \\
\text { sexual IPV }\end{array}$ & 3.16 & {$[1.35,7.42]$} & $<.01$ & 3.25 & {$[1.34,7.87]$} & $<.01$ \\
\hline Recent emotional IPV & 5.08 & {$[2.3 \mathrm{I}, 1 \mathrm{I} .20]$} & $<.01$ & 5.14 & {$[2.35,11.27]$} & $<.01$ \\
\hline $\begin{array}{l}\text { Multiple forms of } \\
\text { recent IPV }\end{array}$ & 3.17 & {$[1.30,7.70]$} & .01 & 3.85 & {$[1.54,9.47]$} & $<.01$ \\
\hline Age & 0.96 & {$[0.94,0.99]$} & $<.01$ & 0.94 & {$[0.91,0.98]$} & $<.01$ \\
\hline Ethnicity & 0.63 & {$[0.40,0.97]$} & .04 & 1.08 & {$[0.80,1.46]$} & .61 \\
\hline School SO bullying & 1.12 & {$[0.71,1.76]$} & .64 & 1.04 & {$[0.61,1.77]$} & 0.89 \\
\hline MSM stigma & 1.52 & {$[0.89,2.61]$} & .13 & 1.74 & {$[0.95,3.18]$} & 0.07 \\
\hline Nondisclosed SO & 1.78 & {$[0.75,4.26]$} & .19 & 0.96 & {$[0.32,2.93]$} & 0.95 \\
\hline Substance use & 1.07 & {$[0.50,2.32]$} & .86 & 1.41 & {$[0.61,3.25]$} & 0.43 \\
\hline Alcohol Use Disorder & 2.05 & {$[1.26,3.35]$} & $<.01$ & 1.93 & {$[1.11,3.36]$} & 0.02 \\
\hline Depression & 9.82 & {$[5.43,17.75]$} & $<.01$ & - & - & - \\
\hline Anxiety & - & - & - & 9.82 & {$[5.43,17.75]$} & $<0.01$ \\
\hline
\end{tabular}

Note. $\mathrm{OR}=$ odds ratio; $\mathrm{Cl}=$ confidence interval; Recent IPV $=$ over past 12 months; $\mathrm{SO}=$ sexual orientation; $\mathrm{MSM}=$ men who have sex with men. Bold values are statistically significant $p$ values of less than or equal to 0.05 . 
Table 4. Odds of Anxiety or Depression Among MSM Living With HIV in Guatemala by Experiences of Any Form of Lifetime IPV Victimization $(n=374)$.

\begin{tabular}{|c|c|c|c|c|c|c|}
\hline \multirow[b]{2}{*}{ Model I } & \multicolumn{3}{|c|}{ Anxiety } & \multicolumn{3}{|c|}{ Depression } \\
\hline & OR & $95 \% \mathrm{Cl}$ & $p$ Value & OR & $95 \% \mathrm{Cl}$ & $p$ Value \\
\hline Any lifetime IPV & 1.86 & {$[1.03,3.38]$} & .04 & 2.02 & {$[1.02,3.99]$} & .04 \\
\hline Age & 0.97 & {$[0.95,1.00]$} & .09 & 0.95 & {$[0.91,0.98]$} & $<.01$ \\
\hline Ethnicity & 0.49 & {$[0.29,0.80]$} & $<.01$ & 1.3 & {$[0.92,1.83]$} & .13 \\
\hline Alcohol Use Disorder & 1.80 & {$[0.10,3.23]$} & .05 & 1.12 & {$[0.57,2.20]$} & .74 \\
\hline Drug Use & 0.64 & {$[0.25,1.62]$} & .35 & 1.01 & {$[0.37,3.05]$} & .91 \\
\hline Nondisclosure of SO & 2.64 & {$[0.93,7.48]$} & .07 & 0.71 & {$[0.18,2.66]$} & $.6 \mathrm{I}$ \\
\hline School SO bullying & 0.97 & {$[0.55,1.71]$} & .92 & 0.75 & {$[0.39,1.45]$} & .39 \\
\hline MSM stigma & 1.35 & {$[0.69,2.61]$} & .38 & 1.31 & {$[0.63,2.7 I]$} & .48 \\
\hline Depression & 9.00 & {$[4.71,17.20]$} & $<.01$ & - & - & - \\
\hline Anxiety & - & - & - & 8.74 & {$[4.59,16.66]$} & $<.01$ \\
\hline
\end{tabular}

Note. $\mathrm{OR}=$ odds ratio; $\mathrm{Cl}=$ confidence interval; $\mathrm{IPV}=$ intimate partner violence; $\mathrm{SO}=$ sexual orientation; $M S M=$ men who have sex with men. Bold values are statistically significant $p$ values of less than or equal to 0.05 .

but not depression (Table 5). Recent physical or sexual IPV was not associated with anxiety or depression.

\section{Discussion}

Among MSM living with HIV in Guatemala City, we found a high prevalence of anxiety, depression, and lifetime IPV victimization. Our finding that $28.6 \%$ of the participants reported any form of lifetime IPV victimization is comparable to levels found in studies among MSM in other settings that used similar measures of IPV, which range from $32.4 \%$ to $44.5 \%$ (Houston \& McKirnan, 2007; Koblin et al., 2006; Welles et al., 2011). The prevalence we found is much lower, however, compared to that found by Pantalone who identified $78.0 \%$ lifetime IPV victimization among MSM living with HIV using the 27-item Revised Conflict Tactics Scale (CTS2) (Pantalone et al., 2012; Straus et al., 1996). This difference may be due, in part, to the wider range of experiences of violence assessed with the CTS2 compared to the measures we used. We found that emotional IPV was the most common form of recent IPV victimization in our study population, followed by physical and sexual IPV. When compared to the one other study among MSM that used a similar instrument to measure different forms of 
Table 5. Odds of Anxiety or Depression Among MSM Living With HIV in Guatemala by Experiences of Recent (Past 12 Months) Physical or Sexual and Emotional IPV Victimization $(n=374)$.

\begin{tabular}{|c|c|c|c|c|c|c|}
\hline \multirow[b]{2}{*}{ Model 2} & \multicolumn{3}{|c|}{ Anxiety } & \multicolumn{3}{|c|}{ Depression } \\
\hline & OR & $95 \% \mathrm{Cl}$ & $p$ Value & OR & $95 \% \mathrm{Cl}$ & $p$ Value \\
\hline \multicolumn{7}{|l|}{ Without covariates: } \\
\hline $\begin{array}{l}\text { Recent physical } \\
\text { or sexual IPV }\end{array}$ & 0.70 & {$[0.18,2.74]$} & .61 & 0.69 & {$[0.17,2.73]$} & .59 \\
\hline Recent emotional IPV & 6.40 & {$[1.92,21.31]$} & $<.01$ & 6.56 & {$[1.99,21.55]$} & $<.01$ \\
\hline \multicolumn{7}{|l|}{ With covariates: } \\
\hline $\begin{array}{l}\text { Recent physical } \\
\text { or sexual IPV }\end{array}$ & 0.54 & {$[0.10,2.96]$} & .48 & 0.94 & {$[0.20,4.53]$} & .94 \\
\hline Recent emotional IPV & 7.23 & {$[1.46,38.85]$} & .02 & 2.29 & {$[0.57,9.23]$} & .24 \\
\hline Age & 0.98 & {$[0.95,1.01]$} & .19 & 0.95 & {$[0.92,0.99]$} & .02 \\
\hline Ethnicity & 0.42 & {$[0.24,0.73]$} & $<.01$ & 1.27 & {$[0.89,1.81]$} & .18 \\
\hline Alcohol Use Disorder & 1.91 & {$[1.05,3.45]$} & .03 & 1.16 & {$[0.59,2.30]$} & .66 \\
\hline Drug use & 0.59 & {$[0.23,1.57]$} & .29 & 1.09 & {$[0.38,3.17]$} & .87 \\
\hline Nondisclosure of SO & 2.87 & {$[1.02,8.09]$} & .05 & 0.74 & {$[0.19,2.79]$} & .65 \\
\hline School SO bullying & 1.03 & {$[0.58,1.82]$} & .93 & 0.81 & {$[0.42,1.56]$} & .52 \\
\hline MSM stigma & 1.26 & {$[0.64,2.49]$} & .52 & 1.34 & {$[0.64,2.81]$} & .44 \\
\hline Depression & 8.88 & {$[4.61,17.10]$} & $<.01$ & - & - & - \\
\hline Anxiety & - & - & - & 8.53 & {$[4.44,16.39]$} & $<.01$ \\
\hline
\end{tabular}

Note. $\mathrm{OR}=$ odds ratio; $\mathrm{Cl}=$ confidence interval; Recent IPV =over past 12 months; $\mathrm{SO}=$ sexual orientation; $\mathrm{MSM}=$ men who have sex with men. Bold values are statistically significant $p$ values of less than or equal to 0.05 .

recent IPV, the prevalence from our sample was somewhat lower for recent physical IPV (5.9\% vs. $11.8 \%)$ and recent sexual IPV $(1.9 \%$ vs. $7.3 \%$ ) (Stephenson et al., 2010). This may be due to social desirability bias, as our survey was conducted in person and the Stephenson study was conducted online (Visschers et al., 2017). In general, our findings may be an underestimation of prevalence given that we were only able to assess a limited number of IPV acts. Future studies that aim to measure IPV prevalence among MSM should consider using the CTS2 instrument in order to capture a wider variation of experiences of IPV victimization.

Our findings echo previous studies indicating that MSM who experience lifetime IPV victimization have higher odds of reporting depressive symptoms (Buller et al., 2014; Houston \& McKirnan, 2007; Mimiaga et al., 2015; Siemieniuk et al., 2013). To our knowledge, ours is the first study to find that lifetime IPV victimization is 
significantly associated with anxiety among MSM. One other study of MSM found a higher likelihood of anxiety disorder among patients who experienced lifetime IPV, but this finding was not significant $(\mathrm{APR}=1.82 ; 95 \% \mathrm{CI}=[0.98,3.40])$ (Siemieniuk et al., 2013). This is important as anxiety disorders are associated with poor quality of life and antiretroviral therapy (ART) nonadherence, among other negative health outcomes experienced by MSM living with HIV (Blashill et al., 2011). Our finding that recent IPV had a greater effect on anxiety compared to lifetime IPV can likely be attributed to the greater proximity of the recent IPV event to the time point at which we assessed mental health outcomes. With time, IPV survivors process their experiences and may seek and receive support that buffers the impacts of victimization on mental health outcomes (Lindhorst \& Beadnell, 2011).

We found that recent emotional IPV may have unique effects on anxiety among MSM living with HIV. This is consistent with research among cisgender women that suggest that emotional violence is particularly harmful and may lead to poorer mental health outcomes compared to other forms of IPV (Pico-Alfonso et al., 2006; Wong et al., 2011). This is also supported by qualitative work by Woodyatt and Stephenson (2016) in which MSM perceived emotional violence to be more harmful than other forms of violence because of its lasting impact. They found that MSM experience unique factors that may make emotional IPV especially detrimental, such as concealing one's SO. Our findings corroborate this claim as MSM in our sample who had not disclosed their SO had nearly three times the odds of reporting anxiety. This is further supported by the MST, which posits that sexual minorities are subject to chronic stressors, above and beyond stressors experienced by the general population, because of the stigmatization they experience associated with their minority status (Meyer, 1995). Experiencing these stressors, while simultaneously lacking social support due to SO concealment, may exacerbate effects of harmful events, such as IPV, on mental health outcomes (Meyer, 2007). In addition, MSM living with HIV may be especially vulnerable to the effects of emotional violence due to the intersecting forms of stigma they experience because of their SO and HIV status.

Taken together, our findings suggest that to improve the mental health of MSM living with HIV, HIV clinics and other health services should screen for IPV victimization and provide appropriate support for victims. Our results also suggest that this support should address both recent and earlier experiences of IPV, although additional studies that include nonoverlapping measures of lifetime and recent IPV would be needed to draw this conclusion. 
There are several limitations to our study. Due to the cross-sectional nature of our data, we are unable to assess the causation and low power may have impacted our ability to see the effects for recent physical or sexual IPV. Future research on IPV victimization and mental health among MSM should use longitudinal designs to assess causality with larger samples, as mental health problems could increase vulnerability to IPV victimization. In addition, as all participants were recruited from the HIV clinic and connected to the health care system, our findings may not be generalizable to MSM living with HIV not in care. Future research should also consider exploring mental health as a mediating pathway between IPV victimization and HIV outcomes to more clearly understand these relationships and potential intervention areas. In the one study among MSM living with HIV that has done this, Pantalone and colleagues found that a greater frequency of IPV victimization was associated with more frequent and severe mental health problems and that having more mental health problems was, in turn, related to ART adherence and HIV viral load (Pantalone et al., 2010). Qualitative research among MSM living with HIV should also be conducted to explore the complex relationship between HIV status and IPV, including the role that relationship power, internalized homophobia, sexual coercion and mutual perpetration may play (Kubicek, 2018).

\section{Conclusion}

MSM living with HIV in Guatemala experience a high burden of anxiety, depression, and IPV victimization. Experiencing lifetime IPV and recent emotional IPV may contribute to higher levels of anxiety and depression. To improve mental health, HIV clinics and other health services should provide support for MSM who have experienced IPV. Future research should examine mental health as a potential mediating pathway between IPV victimization and HIV treatment and adherence outcomes for MSM.

\section{Acknowledgments}

We would like to thank the study participants for sharing their experiences and taking part in the study.

\section{Declaration of Conflicting Interests}

The author(s) declared no potential conflicts of interest with respect to the research, authorship, and/or publication of this article. 


\section{Funding}

The author(s) disclosed receipt of the following financial support for the research, authorship, and/or publication of this article: This study was funded by the President's Emergency Plan for AIDS Relief (PEPFAR) through the Centers for Disease Control and Prevention (CDC) under the terms of Cooperative Research Agreement \#1U01GH001003-05. Davis and Rock were supported by the UNC HIV/STI T32 Training Program (NIH grant \# T32 AI 007001) during the writing of this manuscript. The findings and conclusions in this manuscript are those of the authors and do not necessarily represent the official position of the funding agencies.

\section{ORCID iD}

Dirk A. Davis (D) https://orcid.org/0000-0002-7056-427X

\section{References}

Baker, N. L., Buick, J. D., Kim, S. R., Moniz, S., \& Nava, K. L. (2013). Lessons from examining same-sex intimate partner violence. Sex Roles, 69, 182-192. https://doi.org/10.1007/s11199-012-0218-3

Barrington, C., Santa Luce, R., Guzman, K., Pajarito, Y., Alvis, J., Murray, C., Calderon, M. (2020). Strengthening the "Reach-Test-Treat-Retain" cascade for men who have sex with men in Guatemala: A pilot intervention. Centers for Disease Control and Prevention (CDC).

Batchelder, A. W., Safren, S., Mitchell, A. D., Ivardic, I., \& O'Cleirigh, C. (2017). Mental health in 2020 for men who have sex with men in the United States. Sexual Health, 14(1), 59-71. https://doi.org/10.1071/SH16083

Blashill, A. J., Perry, N., \& Safren, S. A. (2011). Mental health: A focus on stress, coping, and mental illness as it relates to treatment retention, adherence, and other health outcomes. Current HIV/AIDS Reports, 8(4), 215-222. https://doi.org/10.1007/s11904-011-0089-1

Brandt, C., Safren, S. A., Gonzalez, A., Zvolensky, M. J., O'Cleirigh, C. M., \& Woods, S. P. (2016). Anxiety symptoms and disorders among adults living with HIV and AIDS: A critical review and integrative synthesis of the empirical literature. Clinical Psychology Review, 51, 164-184. https://doi.org/10. 1016/j.cpr.2016.11.005

Buller, A. M., Devries, K. M., Howard, L. M., \& Bacchus, L. J. (2014). Associations between intimate partner violence and health among men who have sex with men: A systematic review and meta-analysis. PLOS Medicine, 11(3), Article e1001609. https://doi.org/10.1371/journal.pmed. 1001609

Campos, L. N., Guimarães, M. D. C., \& Remien, R. H. (2010). Anxiety and depression symptoms as risk factors for non-adherence to antiretroviral 
therapy in Brazil. AIDS and Behavior, 14(2), 289-299. https://doi.org/10. 1007/s10461-008-9435-8

Cannon, C., \& Buttell, F. (2015). Illusion of inclusion: The failure of the gender paradigm to account for intimate partner violence in LGBT relationships. Partner Abuse, 6(1), 65-77. https://doi.org/10.1891/1946-6560.6.1.65

Cochran, S. D., \& Mays, V. M. (2009). Burden of psychiatric morbidity among lesbian, gay, and bisexual individuals in the California Quality of Life Survey. Journal of Abnormal Psychology, 118(3), 647-658. https://doi.org/ 10.1037/a0016501.Burden

Dyer, T. P., Shoptaw, S., Guadamuz, T. E., Plankey, M., Kao, U., Ostrow, D., Stall, R. (2012). Application of syndemic theory to black men who have sex with men in the Multicenter AIDS Cohort Study. Journal of Urban Health, 89(4), 697-708. https://doi.org/10.1007/s11524-012-9674-x

Finneran, C., \& Stephenson, R. (2013). Intimate partner violence among men who have sex with men: A systematic review. Trauma, Violence, \& Abuse, 14(2), 168-185. https://doi.org/10.1177/1524838012470034

Friedman, M. R., Stall, R., Silvestre, A. J., Wei, C., Shoptaw, S., Herrick, A., Plankey, M. W. (2015). Effects of syndemics on HIV viral load and medication adherence in the multicentre AIDS cohort study. AIDS, 29(9), 1087-1096. https://doi.org/10.1097/QAD.0000000000000657

Greenwood, G. L., Relf, M. V., Huang, B., Pollack, L. M., Canchola, J. A., \& Catania, J. A. (2002). Battering victimization among a probability-based sample of men who have sex with men. American Journal of Public Health, 92(12), 1964-1969. https://doi.org/10.2105/AJPH.92.12.1964

Guardado Escobar, M. E., Oliva, S., Hernandez, M., \& Peren, J. (2017). Medición de prevalencia, comportamiento, actitudes y prácticas en poblaciones de mayor riesgo al VIH-Sida en Guatemala [Measurement of prevalence, behavior, attitudes and practices among populations at high risk of HIV/ AIDS in Guatemala], 2017. http://hivos.org.gt/wp-content/uploads/2017/08/ Informe-linea-final-Tephinet-020817-1.pdf

Houston, E., \& McKirnan, D. J. (2007). Intimate partner abuse among gay and bisexual men: Risk correlates and health outcomes. Journal of Urban Health, 84(5), 681-690. https://doi.org/10.1007/s11524-007-9188-0

King, M., Semlyen, J., Tai, S. S., Killaspy, H., Osborn, D., Popelyuk, D., \& Nazareth, I. (2008). A systematic review of mental disorder, suicide, and deliberate self harm in lesbian, gay and bisexual people. BMC Psychiatry, 8 , Article 70.

Koblin, B. A., Torian, L., Xu, G., Guilin, V., Makki, H., MacKellar, D., \& Valleroy, L. (2006). Violence and HIV-related risk among young men who have sex with men. AIDS Care, 18(8), 961-967. https://doi.org/10.1080/ 09540120500467182

Kroenke, K., Spitzer, R. L., \& Williams, J. B. W. (2003). The Patient Health Questionnaire-2: Validity of a two-item depression screener. Medical Care, 41(11), 1284-1292. https://doi.org/10.1097/01.MLR.0000093487.78664.3C 
Kubicek, K. (2018). Setting an agenda to address intimate partner violence among young men who have sex with men: A conceptual model and review. Trauma, Violence, \& Abuse, 19(4), 473-487. https://doi.org/10.1177/1524838016673599

Letellier, P. (1994). Gay and bisexual male domestic violence victimization: Challenges to feminist theory and responses to violence. Violence and Victims, 9(2), 95-106. http://libproxy.lib.unc.edu/login?url=http://search. proquest.com/docview $/ 208554833$ ?accountid $=14244$

Lindhorst, T., \& Beadnell, B. (2011). The long arc of recovery: Characterizing intimate partner violence and its psychosocial effects across 17 years. Violence Against Women, 17(4), 480-499. https://doi.org/10.1177/1077801211404548

McKay, T., Lindquist, C. H., \& Misra, S. (2017). Understanding (and acting on) 20 years of research on violence and LGBTQ + communities. Trauma, Violence, \& Abuse, 20(5), 665-678. https://doi.org/10.1177/1524838017728708

McNamee, H., Lloyd, K., \& Schubotz, D. (2008). Same sex attraction, homophobic bullying and mental health of young people in Northern Ireland. Journal of Youth Studies, 11(1), 33-46. https://doi.org/10.1080/13676260701726222

Meyer, I. H. (1995). Minority stress and mental health in gay men. Journal of Health and Social Behavior, 36(1), 38-56.

Meyer, I. H. (2007). Prejudice, social stress, and mental health in lesbian, gay, and bisexual populations: Conceptual issues and research evidence. Psychological Bulletin, 129(5), 674-697. https://doi.org/10.1037/0033-2909.129.5.674

Mimiaga, M. J., Biello, K. B., Robertson, A. M., Oldenburg, C. E., Rosenberger, J. G., O'Cleirigh, C., Safren, S. A. (2015). High prevalence of multiple syndemic conditions associated with sexual risk behavior and HIV infection among a large sample of Spanish- and Portuguese-speaking men who have sex with men in Latin America. Archives of Sexual Behavior, 44(7), 1869-1878. https://doi.org/10.1007/s10508-015-0488-2

O'Cleirigh, C., Magidson, J. F., Skeer, M., Mayer, K. H., \& Safren, S. A. (2015). Prevalence of psychiatric and substance abuse symptomatology among HIVinfected gay and bisexual men in HIV primary care. Psychosomatics, 56(5), 470-478. https://doi.org/10.1017/S0950268814002131.Tuberculosis

O'Cleirigh, C., Newcomb, M. E., Mayer, K. H., Skeer, M., Traeger, L., \& Safren, S. A. (2013). Moderate levels of depression predict sexual transmission risk in HIV-infected MSM: A longitudinal analysis of data from six sites involved in a "prevention for positives" study. AIDS and Behavior, 17(5), 1764-1769. https://doi.org/10.1007/s10461-013-0462-8

Pantalone, D. W., Hessler, D. M., \& Simoni, J. M. (2010). Mental health pathways from interpersonal violence to health-related outcomes in HIV-positive sexual minority men. Journal of Consulting and Clinical Psychology, 78(3), 387-397. https://doi.org/10.1037/a0019307

Pantalone, D. W., Rood, B. A., Morris, B. W., \& Simoni, J. M. (2014). A systematic review of the frequency and correlates of partner abuse in HIVinfected women and men who partner with men. Journal of the Association of 
Nurses in AIDS Care, 25(Suppl. 1), S15-S35. https://doi.org/10.1016/j.jana. 2013.04.003

Pantalone, D. W., Schneider, K. L., Valentine, S. E., \& Simoni, J. M. (2012). Investigating partner abuse among HIV-positive men who have sex with men. AIDS and Behavior, 16(4), 1031-1043. https://doi.org/10.1007/ s10461-011-0011-2

Pico-Alfonso, M. A., Garcia-Linares, M. I., Celda-Navarro, N., Blasco-Ros, C., Echeburúa, E., \& Martinez, M. (2006). The impact of physical, psychological, and sexual intimate male partner violence on women's mental health: Depressive symptoms, posttraumatic stress disorder, state anxiety, and suicide. Journal of Women's Health, 15(5), 599-611.

Plummer, F., Manea, L., Trepel, D., \& McMillan, D. (2016). Screening for anxiety disorders with the GAD-7 and GAD-2: A systematic review and diagnostic meta-analysis. General Hospital Psychiatry, 39, 24-31. https:// doi.org/10.1016/j.genhosppsych.2015.11.005

Russell, S. T., Rya, C., Toomey, R. B., Diaz, R. M., \& Sanchez, J. (2011). Lesbian, gay, bisexual, and transgender adolescent school victimization: Implications for young adult health. Journal of School Health, 81(5), 223-230. Siemieniuk, R., Miller, P., Woodman, K., Ko, K., Krentz, H., \& Gill, M. (2013). Prevalence, clinical associations, and impact of intimate partner violence among HIV-infected gay and bisexual men: A population-based study. HIV Medicine, 14(5), 293-302. https://doi.org/10.1111/hiv.12005

Stall, R., Mills, T. C., Williamson, J., Hart, T., Greenwood, G., Paul, J., Catania, J. A. (2003). Association of co-occurring psychosocial health problems and increased vulnerability to HIV/AIDS among urban men who have sex with men. American Journal of Public Health, 93(6), 939-942. https://doi. org/10.2105/AJPH.93.6.939

Stephenson, R., Khosropour, C., \& Sullivan, P. (2010). Reporting of intimate partner violence among men who have sex with men in an online survey. The Western Journal of Emergency Medicine, 11(3), 242-246. http://www.pub medcentral.nih.gov/articlerender.fcgi?artid $=2941360 \&$ tool $=$ pmcen trez\&rendertype $=$ abstract

Straus, M., Hamby, S., Boney-McCoy, S., \& Sugarman, D. (1996). The Revised Conflict Tactics Scales (CTS2): Development and preliminary psychometric data. Journal of Family Issues, 1(3), 17283-17316.

United Nations Human Rights Council. (2018). Annual report of the United Nations High Commissioner for Human Rights on the activities of the Office of the High Commissioner in Guatemala.

Visschers, J., Jaspaert, E., \& Vervaeke, G. (2017). Social desirability in intimate partner violence and relationship satisfaction reports: An exploratory analysis. Journal of Interpersonal Violence, 32(9), 1401-1420. https://doi.org/10. $1177 / 0886260515588922$ 
Welles, S. L., Corbin, T. J., Rich, J. A., Reed, E., \& Raj, A. (2011). Intimate partner violence among men having sex with men, women, or both: Earlylife sexual and physical abuse as antecedents. Journal of Community Health, 36(3), 477-485. https://doi.org/10.1007/s10900-010-9331-9

Wheeler, J., Anfinson, K., Valvert, D., \& Lungo, S. (2014). Is violence associated with increased risk behavior among MSM? Evidence from a population-based survey conducted across nine cities in Central America. Global Health Action, 7(1), 1-12. https://doi.org/10.3402/gha.v7.24814

Wong, J. Y. H., Tiwari, A., Fong, D. Y. T., Humphreys, J., \& Bullock, L. (2011). Depression among women experiencing intimate partner violence in a Chinese community. Nursing Research, 60(1), 58-65. https://doi.org/ 10.1097/NNR.0b013e3182002a7c

Woodyatt, C. R., \& Stephenson, R. (2016). Emotional intimate partner violence experienced by men in same-sex relationships. Culture, Health and Sexuality, 18(10), 1137-1149. https://doi.org/10.1080/13691058.2016.1175027

World Health Organization. (2002). World report on violence and health. https:// doi.org/10.1136/ip.9.1.93

\section{Author Biographies}

Dirk A. Davis, MPH, is a PhD student at the University of North Carolina at Chapel Hill. His research focuses on identifying and reducing health inequities experienced by sexual and gender minorities in Latin America. He is interested in the intersections of HIV, violence, and mental health among gay, bisexual, and other men who have sex with men and transgender women.

Amelia Rock, MS, is a PhD student in Health Behavior at the University of North Carolina at Chapel Hill. Her research focuses on (a) social and structural determinants of sexual and reproductive health, especially gender, economic opportunity, partner violence, and stigma; (b) HIV prevention and access to treatment and care; (c) evaluation of social and structural interventions.

Renato Santa Luce, MD, MPH, was a project coordinator and Country Representative for the Central American Regional HIV Program at the Universidad del Valle de Guatemala. In addition to coordinating a Key Population Implementation Science study among MSM in Guatemala, he supported the Ministry of Health's strategy to provide decentralized and differentiated HIV care for key populations in the country.

Luz McNaughton-Reyes, $\mathrm{PhD}, \mathrm{MPH}$, is an assistant professor in the Department of Health Behavior at the University of North Carolina at Chapel Hill. Her research focuses on the etiology and prevention of violence, substance use and sexual risk behaviors across the life course, with a particular focus on adolescent population. 
Clare Barrington, $\mathrm{PhD}$, is an associate professor in the Department of Health Behavior at the University of North Carolina at Chapel Hill. She conducts mixed-methods research to examine the social network and structural influences on health, with a focus on HIV prevention and care among female sex workers, men who have sex with men, and transgender women in Latin America. 